\title{
Writing Lived Experience - A Melancholy Elegy
}

\author{
Ying Liu ${ }^{1}$ \\ De Montfort University \\ University of Edinburgh
}

\begin{abstract}
This paper explores the limitations of language in psychotherapeutic writing about lived experience and how psychanalytic concepts can help us both understand and work through the inevitable loss that results from these limitations. It is illustrated by the author's experience of undertaking a doctoral research project in psychotherapy where the experience of narrative incoherence was explored through writing. Paralleled to the doctoral research project was the challenges the author faced in writing the experience of incoherence. By reflecting on and analysing these challenges, this paper explores the sense of loss that is located at the core of writing lived experience through psychoanalytic concepts including the third position and melancholia. Light is shed on the limitations of language in capturing the fullness of lived experienced. Connecting the psychoanalytic concept of melancholia to Romanyshyn's (2013) writing as elegy, this paper proposes writing lived experience as a melancholy elegy in which what is lost in language can be acknowledged and kept alive in the writer's psyche. The continuous engagement with the sense of loss in writing lived experience as a source for creative power and an ethical commitment are discussed.
\end{abstract}

\section{Introduction}

I often struggle with telling 'coherent stories' of my own and articulating my experience. While coherent narrative is widely seen as closely related to one's sense of self and identity (e.g., Adler, 2012; Baerger \& McAdams, 1999) and as an indication for psychological well-being (e.g., Baerger \& McAdams, 1999), it is often the demand for a coherent narrative and articulation that brings me anguish. There is experience deeply felt but somehow unspeakable and inarticulable. Insisting on articulating them in linear form, in my experience, can be a violent act of imposition and alienation. My personal struggles with telling coherent stories and articulating lived experience drove me to write my doctoral thesis on the theme of narrative in/coherence (see Liu, 2019). My thesis questions the dominant emphasis on language and narrative, especially coherent narrative, in psychotherapy. I enquired into the lived experience of narrative incoherence in psychotherapy and sought to honour those moments when words fail us.

Because I was researching into the incoherent, the unspeakable, and the unnarratable, instead of asking others to tell me their experience, I engaged in a process of in-depth experiential self-searching. In this process, I found myself naturally engaging in

${ }^{1}$ Correspondence concerning this article should be addressed Ying Liu, Faculty of Health and Life Sciences, School of Applied Social Sciences, De Montfort University, The Gateway, Leicester, LE1 9BHEmail: ying.liu@dmu.ac.uk

Language and Psychoanalysis, 2020, 9 (1), 55-67.

http://dx.doi.org/10.7565/landp.v9i1.1704 
writing as inquiry (Richardson, 1997, 2000; Richardson \& St. Pierre, 2005) where my writing was not a final presentation of what had been done or discovered but a process of discovering, a process where my "thoughts happened in the writing" (Richardson $\&$ St. Pierre, 2005, p. 972). I wrote from and into the experience of incoherence, the unspeakable and the unnarratable. Writing took me to places of my inner world that I was not aware of previously and contributed to the everchanging interior of my world. The writing was thrilling and yet unsettling. What troubled me was the conflict between the nature of what I was researching - what is beyond language - and the nature of writing.

The underlying belief of writing as inquiry is that "language matters" (Pelias, 2011, p. 660). Another idea perhaps embedded in writing is to establish order: "[s]imply to line up words one after another upon a page is to create some order where it did not exist, to give recognisable shape to the sadness and chaos of our lives" (Smith, 2007, cited in Pelias, 2011, p. 660). This quote cited by Pelias, one of the pioneers in writing as inquiry, suggests that the process of writing is ordering and giving shape to our experience. This is similar to the widely suggested and often accepted therapeutic effect of narrative and story-telling in psychotherapy. Narrative coherence is often viewed as a positive outcome or the goal of psychotherapy (Angus \& McLeod, 2004), which was what I challenged in my thesis. I was confronted by the challenge or even impossibility of languaging what cannot be languaged.

Could I write about the fragmented in the language of order? Could I write about the unknown in a recognisable shape? Could I give words to what is beyond language? Throughout the process of researching into the experience of narrative incoherence, the more I wrote, the more I sensed what could not be written. I recognised in my thesis a melancholic attachment to the unspeakable that was lost in my writing. Throughout the thesis is the presence of the absence, the "unspeakable absence" of loss as an 'ineffable presence' (Stillwaggon, 2017, p. 60). When it was pointed out in my viva that I wrote about the incoherence in such a coherent way, I recognised that something could not be captured and communicated through my writing. Writing, therefore, is not only creating, recording or presenting, but also a process of mourning for what cannot be written.

This paper delves into the loss of what cannot be written in language when we write about lived experience. I will firstly examine the gap between being in the lived experience and symbolisation of the lived experience through a psychoanalytic concept, the third position (Britton, 1993), shedding light on the inevitable loss and pain brought by the symbolisation of lived experience. Reflecting on my experience of writing for my thesis, I will then move on to discuss how the order and linearity of language miss out the formless realm of lived experience. Based on these discussions, I draw on Romanyshyn's (2013) proposal of writing as elegy and the psychoanalytic concept of melancholia (Freud, 2005) to encourage writers and researchers of lived experience to keep in mind the inevitable experience of loss that results from the limitation of language. I will discuss the creative potential of melancholia in the writing of lived experience. The last section of this paper proposes writing as a melancholy elegy as an ethical commitment when we write about lived experience. 


\section{Loss in the Separateness}

[I]n that space of transition and transience, where light fades into darkness and darkness begins to shimmer with light, something of the soul is always left behind and needs to be mourned. (Romanyshyn, 2013, p. 30)

In psychodynamic theory, the development of the capacity to symbolise is viewed as closely related to the development of the third position (Bondi, 2013). In early infancy, the child's needs are met without language, and having his/her needs accurately responded to gives the child a sense of omnipotence and merging with the world and the mother or carer (Bondi, 2013; Winnicott, 1960). Later in the development, after the external reality is experienced by the infant, the links that connect the infant to each of the parents separately are confronted by the link between the two parents in which $\mathrm{s} / \mathrm{he}$ is an excluded third (Britton, 1993). The child comes to realise that each of the parents are separate others who do not solely exist for him/her (Bondi, 2013). This position as an observer rather than a participant is the third position (Britton, 1993). Its establishment provides us the capacity for "reflecting on ourselves whilst being ourselves" (Britton, 2004, p. 48). And the achievement of the movement between immersion in lived experience and the third position brings the capacity to symbolise and reflect on our experience (Bondi, 2013).

The concept of the third position and its crucial place in the development of the capacity for symbolisation and reflexivity indicate a separateness, or to borrow Balfour's (2005, p. 51) phrase, a "linked separateness". As Bondi (2013) points out, there is always a gap between the being in the experience and the reflection on or being curious about the experience without which symbolisation is not possible. Thus, there is an implicit acknowledgment in symbolisation that the experience being symbolised has gone and we are no longer at one with that experience (Bondi, 2013). As Colman (2007, p. 22) writes, "a symbol cannot be a symbol of something unless it represents something other than itself. Therefore, the thing that is symbolised must be absent from the symbol". Language as a form of symbolisation intrinsically carries with it the sense of absence and loss.

Moving to the third position is a key developmental experience, from the psychodynamic perspective, yet at the same time, it is also "suffused with unavoidable pain and loss" (Lanman, 2005, p. 147). It shatters our fantasy of a world as an absolute oneness with the mother or carer in which language is not necessary. Obtaining the capacity to reflect on our experiences is to know that "we have lost an archaic sense of one-ness with the world and with ourselves" (Bondi, 2013, p. 15). Elaborating on Kristeva's work, Stillwaggon (2017) explains that the individualisation of the child as they are introduced to language is experienced as a loss by both the mother and the child. It is a loss of the previous identity in the stage where the child's survival is completely dependent on the mother's active presence. There is no return to this identity through language and it brings an unspeakable grief. 
From the perspective of a qualitative researcher, Romanyshyn (2013) points out the complex relation between the discipline of psychology and what it studies - the soul ${ }^{2}$. The difference between "the standpoint of consciousness" and "the reality of the unconscious" determines the problem of language (Romanyshyn, 2013, p. 26). The belief of the unconscious determines that our psychic world is always beyond the reach of language (Romanyshyn, 2013). Drawing on poet Brendan Kennelly's reflection on his struggles to write down his experience with the figure "the man made of rain", Romanyshyn (2013, p. 30) raises that writing down the soul might be similar to applying the language of 'the daylight view of conscious' to the things in 'the night time view of unconscious'. Language use in research that concerns our psychic world is a way of "speaking of meaning as a presence that is haunted by absence" (Romanyshyn, 2013, p. 29).

\section{Loss in the Ordered and Linear}

While writing my doctoral thesis, I was particularly drawn to the limit of language in capturing the fullness of our lived experience in relation to the ordered and linear nature of writing. I came to realise this through my struggle in writing or typing on the computer.

As I walked to the library in a morning which was to be devoted to my thesis writing, I felt a sense of reluctance. I was puzzled, because I had been feeling excited about finding a research direction and eager to read and write. While I attended to this feeling, what appeared in my mind was the computer screen. I imagined myself sitting in front of the computer with the Word document open, struggling to type on the blank screen. I imagined myself starting to type, feeling unsatisfied, deleting and then re-writing. Sometimes I spent a long time 'rehearsing' in my mind before I could type even just one sentence. This is an anxiety-provoking process. However, I then realised that while typing drained me, when I wrote with pen and paper, it was usually a lot more relieving. When I had a spark of inspiration, I had to go for pen and paper even when I was sitting right in front of a computer. Thus, in that morning, I started to wonder (with pen and paper) what this was about, what was my trouble with writing on the computer. I had both my notebook and the Word document in front of me, and then I noticed how neat the words looked on the computer screen.

The words on the screen stood one after another, neat and tidy, straight line, equal spacing. There was no trace of crossing, shifting, inserting; no trace of my process, struggle or excitement. When something was deleted, it was gone. When something was amended, it looked like it had always been how it looked like in the present time. So much was left out in the neat screen text. On searching my way to the research focus and methodology of my doctoral thesis, I handwrote most of the materials. I wrote here and there, with all the crossing, adding and grammar and spelling mistakes. They were 'all over the place'. I wrote thoughts that crossed my mind. I copied the quotes that I loved, and I wrote my responses to them. They were bits and pieces. After I put them in order on the computer screen, the text could never tell this

\footnotetext{
2 The use of the word 'soul' in Jungian theory, on which Romanyshyn's writing is based, has its ambiguity and I interpret Romanyshyn's use of soul here as the totality of psychic world and process (Samuels et al., 1986), including the unconscious.
}

Language and Psychoanalysis, 2020, 9 (1), 55-67. 
'all over the place' and 'bits and pieces'. Sometimes I was surprised when I read the Word documents I typed previously by how ordered and logical they appeared to be. When I read them, I saw a person with a clear mind who knew exactly what she was doing, whereas in my memory I was not like this at all. These texts did not tell the struggles, the putting together, the adding in, the clutter and my messy writing process. There was an academic requirement for me to write in a presentable manner, to cut out the parts that did not fit. It is always comforting to see my thoughts come together as a whole, and that I am making sense thus others can understand me and give feedback, which makes communication possible. However, the parts of me and my process that these neat texts cannot tell are left out and abandoned. Just like the keyboard and computer screen leave behind the messy writing process, writing itself can leave behind the non-linear and messy aspects of the experience being written.

Stierlin (1963) describes us human beings as the heir to the law of causality. Order, coherence and continuity indeed are what we are deeply concerned with and even our sense of self rest on them (Mattingly, 1998). We would love to experience our lives as "personal, generally coherent, emotionally meaningful, narratively knowable, and tellable" (Richardson, 1997, p. 62). However, life lacks form (Frank, 2010; Mink, 1987). As some anthropologists argue, the deep human concern with order and coherence is not in accord with our experience of life (Mattingly, 1998). When we capture our formless life experience with ordered and coherent narrative, we are also taming our experiences (Mattingly, 1998). To quote Mattingly (1998, p. 34), who elaborates on some narrative theories that doubt lived experience and narrative have much to do with each other: "Narrative [...] is a mythical imposition of coherence on what is otherwise formless experience". Writing as a way to establish order (Smith, 2007, cited in Pelias, 2011) is also an imposition of form on the formless aspect of our lived experience. This is another inevitable and painful loss to be recognised in writing lived experience. Writing lived experience is writing down as well as leaving out and cutting off.

\section{Writing as Elegy}

The development of the capacity to reflect and to symbolise and the inadequacy of language in speaking the fullness of our experiential world which includes the unconscious and the formlessness entail a profound sense of loss. Thinking about this loss, I am particularly drawn to one of Romanyshyn's (2013) proposals for qualitative researchers to keep soul in mind while writing down the soul: writing as elegy. In this proposal of elegiac writing, he honours the sense of mourning for what has slipped away, what has been "lost, forgotten, left behind, abandoned, and yet haunts our efforts to know the world and ourselves and to say what we know" (Romanyshyn, 2013 , p. 313). He sees the researcher as the 'failed poet' who 'stands in the gap between the fullness of experience and the 'failure' of language to command it', who "is able to bear the tension between knowing and not knowing" (Romanyshyn, 2013, pp. 9-10).

Poet Louise Glück (2000, cited in Pelias, 2004) says there is nothing more exciting than being able to say fully and exactly about something and to get to the bottom of something. Writing as elegy is to resist the lure of exactitude and relinquish the attempt to reach to the bottom of our experience. To write about lived experience is to write a hymn of lament (Romanyshyn, 2013) for what has been lost in language. It is

Language and Psychoanalysis, 2020, 9 (1), 55-67. 
the necessary grief that Butler (2005) writes about - the necessary grief for the loss of something we never had which is the fully articulate and narratable self. When I wrote about what I could write, I also held in mind what I could not write and the necessary grief for this loss. To add on Romanyshyn's (2009) elegiac writing, writing for me is not only an elegy in which what has been lost is mourned, but also the melancholy attachment to the unknown loss, a refusal to relinquish the unspeakable and unknown that cannot be written.

Early in his essay Mourning and Melancholia, Freud (2005) points out a main difference between mourning and melancholia which is related to the explanation of feeling and behaviour. Freud points out that although mourning and melancholia can bring the same intensity of pain, same level of loss of interest and inhibition of any kind of performance, the only reason why mourning, unlike melancholia, does not strike people as pathological is that it can be easily explained. Freud argues that compared to mourning, in the case of melancholia, the loss is more notional in nature. Mourning can occur for not only the death of a loved one but also for a loss in an abstract form, for example, for freedom or an ideal. However, what is lost is easily identified. In the case of melancholia, the loss may well be a real or concrete loss of a loved one through events such as death. Alternatively, it can be the loss of the loved one as a love-object, for instance, being abandoned. However, in some cases, Freud says, it is difficult to see what has been lost. In other words, the melancholic is not conscious of what has been lost. In some other cases, what or who is lost is clear, but the melancholic is not aware of what it is about that person or that thing $\mathrm{s} / \mathrm{he}$ has lost. Therefore, Freud relates melancholia to the loss of an object which is withdrawn from consciousness, whereas in mourning, "no aspect of the loss is unconscious" (Freud, 2005, p. 205).

This indicates to me how writing and language in general fail in the face of melancholia which is situated in the unknown and the unexplainable. The sense of loss involved in the inadequacy of language in speaking the fullness of our experiential world includes the loss of something unknown to our consciousness. When writing my thesis, I continuously struggled with the inadequacy of writing. My every attempt to use words was "a wholly new start, and a different kind of failure" (Eliot, 1944, p. 21). Something always slipped away in between my words. The bigger struggle, yet, was the impossibility of knowing what had slipped away. The sense of melancholy permeated the whole research project. It often woke me up before the daybreak and led to many writings in vain. I tried to fight against it and to find a solution but realised eventually that it was exactly this impossibility of symbolisation in melancholia (Leader, 2009) that my thesis must contain and that I as a researcher and writer on lived experience needed not only to tolerate but also to cherish.

Leader (2009) explains the melancholic's struggle with language based on Freud's (2005) argument. According to Freud's theory, there are two psychical systems involved in thinking. One is linked to the perception of things which he calls thing representation and the other is linked to words and speech which he terms word representation. Thing representation, which consists of collection of memory traces of things, and word representation, which is constituted by acoustic and semantic aspects of language, are usually linked together. Mourning is made possible through the moving between thing representation and word representation. Through the pathway

Language and Psychoanalysis, 2020, 9 (1), 55-67.

http://dx.doi.org/10.7565/landp.v9i1.1704 
of preconscious, the unconscious ambivalent battle between love and hate towards the lost object is made conscious. In the case of melancholia, this pathway is blocked. Unconscious thing representation cannot be reached through conscious word representation. Therefore, as Leader (2009, p. 189) concludes, "at the heart of melancholia is a problem to do with language. Words and things seem radically separated for the melancholic". A symbolic impasse is then present for the melancholic (Leader, 2009). Leader (2009) identifies in melancholia the failure to speak properly and articulately about the lost object and the individual's relation to it. In the first sentence of her provocatively book Black Sun: Depression and Melancholia, Kristeva (1987) writes about the challenge of writing from the place of melancholia:

For those who are racked by melancholia, writing about it would have meaning only if writing sprang out of that very melancholia. I am trying to address an abyss of sorrow, a noncommunicable grief that at times, and often on a long-term basis, lays claims upon us to the extent of having us lose all interest in words, actions, and even life itself (p. 3).

As Leader (2009) and Kristeva (1987) suggest about melancholia, my words failed to touch their referent.

Freud (2005) suggests that to preserve the loved yet lost object, the melancholic identifies with the object. A choice of identification with the dead or the lost object for the melancholic, according to Leader (2009), is to die with them, physically or psychically. This situates the melancholic in a particular position of in-between two worlds: the world of the dead and the living. It becomes a torment to find words that can describe this dual existence, this impossible experience of being in two places at the same time. This standing in-between two worlds and the impossibility of being in two places at the same time were my struggles as the 'failed poet' (Romanyshyn, 2013). In the melancholia was knowing that I had failed yet not knowing what I had failed.

Freud (2005) thinks that melancholia is related to the unresolved grief in which the lost object cannot be let go. Approaching the (unsatisfying) end of my research project, I identified in the research project the refusal of letting go what had been lost, what could not be known and spoken in my writing about lived experience. I saw my writing as an unconscious melancholic returning to the unknown and the unspeakable. Aligning with Romanyshyn's (2013) proposal of elegiac writing, I propose that writing lived experience inevitably comes with a melancholy sense brought by the loss of what is unknown and unknowable, what is unspoken and unspeakable. This failure of language and perhaps our consciousness needs to be held in the mind of the writer and be constantly engaged with. 


\section{The Creative Potential of Melancholia in Writing Lived Experience}

In Freud's (2005) original conceptualisation of melancholia, the melancholic's identification with the lost object and the refusal to let it go are pathological and damaging. The ego of the melancholic becomes empty (Freud, 2005). However, this view of melancholia as merely pathological has been challenged. For example, in the context of the everyday life of the ethnic minority, Eng and Han (2000) view melancholia as an ethical commitment of the minority and the immigrant to preserve the important yet lost ethnic origin and identity. It is a way of expressing that something is so important that the ego is willing to preserve it at the cost of its own wellbeing (Eng \& Han, 2000). For Eng and Han (2000, p. 695), the melancholic process is one way in which "socially disparaged objects [...] live on in the psychic realm". Eng and Han (2000) see not giving up the lost object too easily as an ethical commitment which holds the power for political change. For me as a researcher and writer of lived experience, what cannot live in written words, I hold it alive in my psychical world by not ignoring it, not fighting against it, not letting it go easily, and acknowledging, living with and engaging with the sense of loss and melancholia during and after the research and writing process. It is an act of refusal to allow what is beyond language and words to "disappear into oblivion" (Eng \& Han, 2000, p. 695). Taking this position holds in mind the fullness of lived experience and declines the false certainty that we can fully know and write about the lived experience that we are delving into.

The creative and productive potential of melancholia has been recognised and discussed (e.g., Eng \& Kazanjian, 2003; Ruti, 2005). Instead of a problem, Brady and Haapala (2003, para. 6) see melancholy as 'a mature emotion in which reflection calms a turbulent soul'. The state of melancholy does not debilitate, instead, Brady and Haapala (2003) argues that it involves the reflection and contemplation of things that we long for and love. In this opportunity for reflection and contemplation lies the productive function of melancholy (Brady \& Haapala, 2003). According to Brady and Haapala (2003), the most distinctive feature of the emotion of melancholy is its involvement of reflection. The reflective feature of melancholy lies on the fact that its object is absent and unattainable and is experienced indirectly through memories, imagination and thoughts (Brady \& Haapala, 2003). Another feature of melancholy is that is it often associated with solitude (Brady \& Haapala, 2003; Burton, 2001). Solitude facilitates the imaginative reflection of melancholy; through imagination which makes links between the past, the present and the future, our reflection is deepened, which in turn deepens our feelings (Brady \& Haapala, 2003).

Its connection to imagination, reflection, contemplation and solitude often makes melancholy an aesthetic emotional state that is appreciated for literature, art and music, but it is seldom written in relation to academic writing. However, isn't writing in qualitative research that delves into lived experience an imaginative, solitary and reflective process? Alone in my room, sitting under the warm orange light of my desk lamp and writing these words in this quiet evening, I am dipping into my emerging thoughts and feelings. As early as in the $17^{\text {th }}$ century, Burton (2001) recognises not only the sadness but also the sweetness or pleasure of melancholia. It is out of the sweet sorrow of melancholy (Brady \& Haapala, 2003) that this paper is produced. 
Instead of a purging of emotion, melancholy is a full and ripe emotion that allows us to indulge into memories, thoughts and imaginations (Brady \& Haapala, 2003).

As Eng and Kazanjian (2003) argue, the productive and creative potential of melancholia lies in its continuous engagement with the loss and its remains. It was the engagement with the loss that is unknowable and unspeakable that gave my thesis creative power. The engagement with the inexpressible loss drove me to end my thesis with a photo of the trace of my touch on the sand. The presence of the absent touch spoke for me the tension between holding on to and letting go and the impossibility of being in two worlds. It spoke for me my lack of full control over the work I produced. It spoke for me the loss of some aspects of self when my experience was written down on paper.

Interestingly, along with other embodied methods, writing was what I naturally turned to when I explored the unspeakable and unnarratable. While experiencing the limitation of language and narrative, it became obvious in my writing that I desired to tell in language. It was the impossibility of expression and the necessity to tell and be known that brought me difficulties. As Edkins (2003, cited in Andrews, 2010, p. 155) says: "[I]t is both impossible to speak, and impossible not to speak". This corresponds to some people's experience of trauma and catastrophe. For example, in his diary about the life in Warsaw Ghetto, Cups of Tears, Abraham Lewin (cited in Andrews, 2010) talks about both the impossibility and the necessity of expressing his thoughts and feelings. As mentioned, a problem for the melancholic is the impossibility of making words to touch their referent, which brings them the self-reproach about not being able to tell with exactitude about the lost object and their relation to it (Leader, 2009). For Leader (2009), the solution (if I can call it so) to this is less about unblocking the passage from things to words than taking the impossibility seriously, "to find words to say how words fail" (p. 191).

Holding in mind this tension between the necessity and impossibility of expression motivates researchers and writers to search for different ways to approach, express and make sense of lived experience. Pelias (2004, p. 78) sees exactitude and closure in writing as tasks that can never be accomplished, and he writes, 'it is the search that matters'. While humbly acknowledging the losses and unbridgeable gaps between language and lived experience, many writers and researchers have made heartwarming and valuable efforts to write down the soul, to show lived experience, to know, to convey meanings and at the same time to allow themselves to be transformed by the writing (e.g., Richardson, 1997; Speedy, 2015).

One of the examples is the use of poetry. Leader (2009) recognises the necessity to speak about loss creatively in a form of language that suits the individual. As Leader (2009) and other authors (e.g., Kempler, 2003; Neilson, 2004, cited in Prendergast, 2009) recognise, this is one of the functions of poetry. Although I had been engaging in non-verbal methods when working on my thesis, I nonetheless had a sense that words were all I had. As Kempler (2003) might say, while non-verbal methods assisted me to experience and express, I was still left fumbling for words to communicate myself. Free from external regulations including the rules of grammar, poetry offers the writer an opportunity to re-invent a language that belongs to his/her own, not one that belongs to one's parents, teachers and others (Kempler, 2003). This feature of poetry responds to my above critique of the linearity of language, offering a

Language and Psychoanalysis, 2020, 9 (1), 55-67.

http://dx.doi.org/10.7565/landp.v9i1.1704 
potential to allow the messiness, the fragmented and the incoherence to show on the paper.

\section{An Ethical Commitment}

The wisest know that the best they can do ... is not good enough. The not so wise, in their accustomed manner, choose to believe there is no problem and that they have solved it. (Malcolm, 1990, cited in Josselson, 1996, p. 71)

The melancholy elegy of writing does not end in consolation. Instead, in writing lived experience, there is always this inevitable and necessary discomfort, about intruding others' lives (Josselson, 1996) or about mispresenting one's own (e.g., Tamas, 2008). As Josselson's (1996) opinion on doing narrative research on others' lives, I believe that writing lived experience, others' or our own, is a work that we need to do in anguish.

The above quote by Malcolm (1990, cited in Josselson, 1996) touched and, more importantly, validated the part of me who has always felt inadequate as a researcher when facing others' and my own unspeakable experience. It comforted me as the 'failed poet' who bears the tension between knowing and not knowing (Romanyshyn, 2013) and who tolerates the losses in the process of symbolisation.

Recognising both the therapeutic and problematic aspects of writing lived experience, Lieblich (2013) asks a question in the end of her article:

[...] a final narrative, put in words and writing, replaced a vivid, quivering, and colorful recollection. Furthermore, the mere writing process, the search for words, phrases, and metaphors for the representation of inner experiences, sometimes changed the memory, adding to or subtracting from the nonverbal, fully alive image one tries to convey. Thus, writing has a price in replacing the unwritten or unnarrated memory, with a final version, a constant "thing." Do we always wish this to happen? (p. 52)

This is a question that I have been asking myself when I write and a question that I do not have an answer to. This tension between the need to write and the loss involved in writing, between the curative effect and the problems of writing was what I had been grappling with in the process of writing my thesis. I could not write without leaving something out and I could not write without replacing the unspeakable with the spoken.

In the research context, therefore, I see the endeavour to write while holding in mind the problems of writing lived experience as an ethical commitment, to our research participants including others and ourselves, our audiences, and ourselves as writers. 
Holding in mind the problem of writing stops us from assuming that we know, or that we can know. It holds us back from asserting that we can speak fully for others and even for ourselves. Being aware of the inadequacy of our language allows us to honour the circumstances and individuals by putting down on paper careful and hardwon words (Neilson, 2004, cited in Prendergast, 2009). By being with the necessary discomfort and anguish (Josselson, 1996), we honour rather than alienate and ignore that which cannot be spoken. This commitment is also the drive for the creative and productive power from which the poetics of research (Hope, 1971; Romanyshyn, 2013) can be generated and from which reflexivity of the researcher springs. It is the engagement with the loss that drive researchers and writers to seek for creative ways, for instance, poetry as mentioned above, to write about lived experience. It is this commitment that allows us to be aware of what we are doing and thus protects us from going too far (Josselson, 1996), and it is this commitment that enables us to keep searching and to dance with the impossibility (Neilson, 2004, cited in Prendergast, 2009).

\section{Conclusion}

Drawing on psychoanalytic concepts including the third position and melancholia, this paper analyses the limitations of language in writing lived experience. The capacity to reflect upon one's experience and symbolise it in language requires separation from one's immediate experience, which brings the unbridgeable gap between one's lived experience and its symbolisation. Meanwhile, the ordered and linear nature of language misses out the realm of lived experience that is formless and structureless. The language of known cannot capture the experience of unknown. Thus, when language is used in writing lived experience, there is always an inevitable loss. This paper argues that writing lived experience, therefore, is also a process of mourning in which the writer of lived experience holds in mind what cannot be written and what slips away. It is this engagement with the inevitable loss and pain that brings the creative potential and deepens our reflection on our unspeakable and unconscious experience. Writing as a melancholy elegy is to acknowledge our words are never good enough when writing down the lived experience, our own or others'. It is a homage to the complexity of human experience much of which cannot be storied, spoken and even imagined.

\section{Reference}

Adler, J. M. (2012). Living into the story: agency and coherence in a longitudinal study of narrative identity development and mental health over the course of psychotherapy. Journal of Personality and Social Psychology, 102, 367-389.

Angus, L. E., \& McLeod, J. (2004). Self-multiplicity and narrative expression in psychotherapy. In H. J. M. Hermans \& G. Dimaggio (Eds.), The dialogical self in psychotherapy (pp. 77-90). New York, NY: Brunner-Routledge.

Andrews, M. (2010). Beyond narrative: the shape of traumatic testimony. In M. Hyvärinen, L. Hydén, M. Saarenheimo \& M. Tamboukou (Eds.), Beyond narrative coherence (pp. 147-166). Amsterdam, The Netherlands: John Benjamins B.V.

Baerger, D. R., \& McAdams, D. P. (1999). Life story coherence and its relation to psychological well-being. Narrative Inquiry, 9, 69-96.

Burton, R. (2001). The anatomy of melancholy. New York, NY: New York Review Books.

Language and Psychoanalysis, 2020, 9 (1), 55-67.

http://dx.doi.org/10.7565/landp.v9i1.1704 
Brady, E., \& Haapala, A. (2003). Melancholy as an aesthetic emotion. Contemporary Aesthetics. Advance online publication. Retrieved from https://contempaesthetics.org/newvolume/pages/article.php?articleID=214\#FN1

Balfour, A. (2005). The couple, their marriage, and Oedipus: or, problems come in twos and threes. In F. Grier (Ed.), Oedipus and the couple (pp. 49-71). London, UK: Karnac.

Britton, R. (1993). The missing link: parental sexuality in the Oedipus complex. In D. Breen (Ed.), The gender conundrum: contemporary psychoanalytic perspectives on masculinity and femininity (pp. 83-96). London, UK: Routledge.

Britton, R. (2004). Subjectivity, objectivity, and triangular space. Psychoanalytic Quarterly, 73, 47-61.

Butler, J. (2005). Giving an account of oneself. New York, NY: Fordham University Press.

Bondi, L. (2013). Research and therapy: generating meaning and feeling gaps. Qualitative Inquiry, 19, 9-19.

Colman, W. (2007). Symbolic conceptions: the idea of the third. Journal of Analytical Psychology, 52, 565-583.

Eliot, T. S. (1944). Four quartets. London, UK: Faber and Faber Limited.

Eng, D. L., \& Han, S. (2000). A dialogue on racial melancholia. Psychoanalytic Dialogues, 10, 667-700.

Eng, D. L., \& Kazanjian, D. (2003). Introduction: mourning remains. In D. L. Eng \& D. Kazanjian (Eds.), Loss: the politics of mourning (pp. 1-25). Berkeley, CA: University of California Press.

Freud, S. (2005). On murder, mourning and melancholia. London, UK: Penguin.

Frank, A. W. (2010). Letting stories breathe: a socio-narratology. Chicago, IL: The University of Chicago Press.

Hope, A. D. (1971). A midsummer eve's dream: variations on a theme by William Dunbar. Edinburgh, UK: Oliver and Boyd.

Josselson, R. (1996) On writing other people's lives: self-analytic reflection of a narrative researcher. In R. Josselson (Ed), Ethics and process in the narrative study of lives. London, UK: Sage.

Kristeva, J. (1987). Black sun: depression and melancholia. New York, NY: Columbia University Press.

Kempler, N. Z. (2003). Finding our voice through poetry and psychotherapy. Journal of Poetry Therapy, 16, 217-220.

Lanman, M. (2005). The painful truth. In F. Grier (Ed.), Oedipus and the couple (pp. 141-162). London, UK: Karnac Books.

Leader, D. (2009). The new black: mourning, melancholia and depression. London, UK: Penguin Books.

Lieblich, A. (2013). Healing plots: writing and reading in life-stories groups. Qualitative Inquiry, 19, 46-52.

Liu, Y. (2019) Sky seen through trees: rethinking narrative coherence in counselling and psychotherapy. Doctoral dissertation. University of Edinburgh, UK. Retrieved from http://hdl.handle.net/1842/36146

Mink, L. O. (1987). Historical understanding. London, UK: Cornell University Press.

Mattingly, C. (1998). Healing dramas and clinical plots: the narrative structure of experience. Cambridge, UK: Cambridge University Press.

Pelias, R. J. (2004). A methodology of the heart: evoking academic and daily life. Walnut Creek, LA: AltaMira Press. 
Pelias, R., J. (2011). Writing into position - strategies for composition and evaluation. In N. K. Denzin \& Y. S. Lincoln (Eds.), The Sage handbook of qualitative research, 4th edition (pp. 659-668). London, UK: Sage.

Prendergast, M. (2009). "Poem is what?" Poetic inquiry in qualitative social science research. International Review of Qualitative Research, 1, 541-568.

Richardson, L. (1997) Fields of play: constructing an academic life. New Brunswick, NJ: Rutgers University Press.

Richardson, L. (2000). Writing, a method of inquiry. In N. K. Denzin \& Y. S. Lincoln, (Eds.), Handbook of qualitative research, 2nd edition (pp. 923-948). London, UK: Sage.

Richardson, L., \& St. Pierre, E. (2005). Writing: a method of inquiry. In N. K. Denzin \& Y. S. Lincoln (Eds.), Handbook of qualitative research, 3rd edition (pp. 959978). London, UK: Sage

Ruti, M. (2005). From melancholia to meaning how to live the past in the present. Psychoanalytic Dialogues, 15, 637-660.

Romanyshyn, R. D. (2013). The wounded researcher: research with soul in mind. New Orleans, LA: Spring Journal Books.

Stierlin, H. (1963). Existentialism meets psychotherapy. Philosophy and Phenomenological Research, 24, 215.

Samuels, A., Shorter, B., \& Plaut, F. (1986). A critical dictionary of Jungian analysis. London: Routledge \& Kegan Paul.

Speedy, J. (2015) Staring at the park: a poetic autoethnographic inquiry. Walnut Creek, CA: Left Coast Press.

Stillwaggon, J. (2017). "A fantasy of untouchable fullness": melancholia and resistance to educational transformation. Educational Theory, 67, 51-66.

Tamas, S. (2008). Writing and righting trauma: troubling the autoethnographic voice. Forum: Qualitative Social Research, 10. Advance online publication. Retrieved from http://www.qualitative-research.net/index.php/fqs/article/view/1211

Winnicott, D. W. (1960). The theory of the parent-infant relationship. The International Journal of Psycho-Analysis, 41, 585-595. 